\title{
Urgences
}

\section{Le gel trace son mime...}

\section{Vianney Gallant}

Numéro 1, 2e trimestre 1981

URI : https://id.erudit.org/iderudit/025011ar

DOI : https://doi.org/10.7202/025011ar

Aller au sommaire du numéro

Éditeur(s)

Urgences

ISSN

0226-9554 (imprimé)

1927-3924 (numérique)

Découvrir la revue

Citer ce document

Gallant, V. (1981). Le gel trace son mime... Urgences, (1), 60-65.

https://doi.org/10.7202/025011ar

Ce document est protégé par la loi sur le droit d'auteur. L'utilisation des services d'Érudit (y compris la reproduction) est assujettie à sa politique d'utilisation que vous pouvez consulter en ligne.

https://apropos.erudit.org/fr/usagers/politique-dutilisation/
Cet article est diffusé et préservé par Érudit.

Érudit est un consortium interuniversitaire sans but lucratif composé de l'Université de Montréal, l'Université Laval et l'Université du Québec à Montréal. Il a pour mission la promotion et la valorisation de la recherche. https://www.erudit.org/fr/ 


\section{Vianney Gallant}


Le gel trace son mime dans l'alambic du miroir la terre a un torticolis un quintette entouré $d$ 'icebergs dans lhistoire dans les moeurs

L'espoir n'est plus qu'un combat où se défient les peurs en carrefour les peurs au sourire aux lèvres dans la toile d'araignée démocratique

L'espoir trace son mime sous le rideau de théâtre le rouge et le noir culminent la grisaille tempête de mots récupérés codifiés dans l'oeil de la grande machine ordinaire

Le gel trace son mime dans l'alambic du miroir entre quatre yeux l'eau de vie silencieuse marée diffuse de critiques mineures enracinées dans le mal de vivre

Ne parlez plus d'êtres fragiles l'émail s'écaille sous les ongles de la frigidité affective Ne parlez plus de souhait la mort est gagnée d'avance dans le moindre trajet

Jouer le mime de l'illusion dans le cadre le plus mnémotechnique le diurne tout noir sur l'horizon aperçu 
Le sanglot sèche dans son désert derrière la rime du siècle

la vie grince et miaule

la clé verte déclique sa nausée

sa dernière secousse

l'odeur pénètre dans la piaule

Le sanglot sèche dans son désert derrière la rime du siècle

le travail a bâti sa loi

la grande hiérarchie de guimauve où le caramel de la retraite règne et le labyrinthe camoufle son angoisse avec la craie du mérite

Le sanglot sèche dans son désert derrière la rime du siècle

l'art se structure en son dernier appel

il gît dans sa descente

comme une pluie de miel

vienne la bureaucratie culturelle

tracer son astucieux marché aux puces

atrophie inconsciente délibérante

momifiant le réel

qui clamait sa naissance

dans le raccourci technique

Le sanglot sèche dans son désert

derrière la rime da siècle

la cendre de l'os sur la dure

la même eraie blanchit toute l'âme

s'effritent les recommencements

sur les balbutiements de conscience 
La porte fermée à double tour mon nez sur la vitre j'essaie de lire le fleuve les gens glissent au dehors comme en jeu d'êtres purs jusqu'à l'île demeurée ville close

Bien au chaud quand seule filtre la beauté ma petite guerre à l'errance grimpe l'édifice sur le toit le bel éteignoir irradie l'ombre un moment d'éclair

La porte fermée à double tour je mesure l'épaisseur de l'autre fenêtre en face de la table que le froid divise comme une rue et circulent des mots de Père Noël je mesure ma capacité de briser l'ombre filtrée jusqu'au mur de la parole la fissure empruntée à un quidam angélique

Tu mets le temps dans la raison fauve l'arc-en-ciel éclate en bribes de couleurs en cristaux bientôt brunis dans le licou intellectuel

Le clair de lune était un néon dans le ministère de la folie la porte fermée à double tour je cherchais la clé pour tordre le fer un peu plus à jamais incendiaire sur la fonte des mirages

Dans la cage sans barreau derrière ma peau lire dans ton ventre de mutant médire la lame désirée l'effroi dans la marge de feu derrière ta peau la même cage sans barreau que lime la parlure noircie cheminée du désastre quand l'un se tait d'amertume

La porte fermée à double tour dans son propre clocher sa propre chapelle sonne le glas chevelure d'aquarelle le temps au galop pour fuir derrière ta peau fermée à double tour 
Lier l'armure à son porteur du corps à l'être

découvert dans chaque pellicule où roule la grande image

ce voyage est un noeud

à défaire 
Doux demain la fleur d'âme

1 hiver a sa feuille dans ma main tout corps à reprendre le dedans

dans l'os

le regard caustique de la structure

au coin magique d'un café

l'onde d'un silence pousse son sifflet

dans l'âtre ton visage

Doux demain la fleur de l'âge

l'hier a son cercueil dans ta main

toute mort se mire sur le passant

à revers de cosmos

la fenêtre du vers qui dissout le murmure

dans la poche du manteau blane

des cristaux fluides sur le dossier

rament des diablelets

l'aveu une image

Doux demain à coeur de mirage

l'évitement de l'égoût en deuil stratégique

ragoût de doigts palmés d'étoiles

sur le sot engagement - fou-rire glacé

miroitant de fuite

le focus de la caméra acoustique

micro élargi sans nervure

à l'iris autrement ramifié

Doux demain ma soeur d'âme

blotti dans le creux de la survie

l'hier hiver fondu dans sa maison

pour l'abri de la fleur de l'âge

dans la racine du sacré

$$
\text { éperdue }
$$

